\title{
Characterization of Surface Coating Techniques for Improved Performance
}

\author{
K. Samhitha Reddy, V. Shreya Reddy, Sujitha. J, Madhuri Pydimalla
}

\begin{abstract}
Surface coating has evolved with time, tracking the demands of the processing industry. This research activity, studies the significance of powder coatings in the evolution of existing conventional surface coating technology for their practical applications in the field of metal coating, particularly office and home appliances. The first objective of this work involves a systematic comparison between polymer powder coatings with liquid-based coatings. In the second objective, a comparison between the polymer coatings with additive filled powder coating was performed. Various conventional substrates (such as copper, aluminium, galvanized iron, brass, cement plank, wood block) were used for this study. The materials were first dry scuffed and then dipped in 3 in 1 chemical (zinc phosphate chemical and magnesium phosphate) for the primer coat. The prepared substrates were surface coated with liquid paint (on one side of the panel) using spray gun and powder paint (on another side of panel) using electrostatic spraying. The coated panels are then subjected to various standard (ISO) characterization techniques such as Scratch hardness test, Flexibility test, Thickness test, Adhesion test, Impact resistance test etc to analyze the effectiveness of the coatings applied. The quantitative and qualitative results thus obtained using powder coatings were promising (e.g: As the load progressively kept increasing i.e. 1000-2000 gm, mild scratches were noticeable on liquid coated substrates whereas powder coated metal panels have shown a greater resistance to scratch damage) as the test values determined high strength quality and durability (in-line with the standards) in comparison with liquid coatings. Also, the doping of additive (graphene) in small quantity has improved characteristics and qualities of the powder coated materials (e.g: graphene based powder coating has endured scratch hardness test beyond 2500 gms load force compared to simple powder coating). The findings of the current research study has confirmed the advantage of the powder coating technology and also deliberated the effect of fine powder flow ability. The important future prospects of this research work is that., powder coatings will stand on the threshold of exciting breakthroughs thus opening new frontiers by being able to coat thick steel components and even non-metal substrates. Also, the recent advances in powder coating technology with anticorrosive additives will result in bonded metallic coatings that deliver a unique, quality appearance.
\end{abstract}

Manuscript Received on May 2020

*Correspondence Author

K. Samhitha Reddy, Chemical Engineering, Chaitanya Bharathi Institute of Technology, Hyderabad, India.

V. Shreya Reddy, Chemical Engineering, Chaitanya Bharathi Institute of Technology, Hyderabad, India.

Sujitha. J, Chemical Engineering, Chaitanya Bharathi Institute of Technology, Hyderabad, India.

Dr. Madhuri Pydimalla*, Chemical Engineering Department, Chaitanya Bharathi Institute of Technology, Hyderabad, India. Email: pmadhuri_chem@cbit.ac.in/pmadhuri262@gmail.com

(C) The Authors. Published by Blue Eyes Intelligence Engineering and Sciences Publication (BEIESP). This is an open access article under the CC BY-NC-ND license (http://creativecommons.org/licenses/by-nc-nd/4.0/)
Keywords: Powder coatings, Additive (graphene), Scratch hardness test, Impact resistance test.

\section{INTRODUCTION}

A coating is a covering that is applied to the surface of an item or substance to enhance and expand a variety of practical performance properties such as colour, shine, wear resistance or chemical attack or permeability [1]. Coatings (also termed as "Substrate") refers to paints such as lacquers or enamels, films such as varnishes, sealants, adhesives, inks, maskants, and temporary protective coatings. Coatings are generally referred to as decorative or protective; often both the functions are included. The design of coatings over the years is primarily aimed to reduce the coating thickness and improve the corrosion resistance [2]. Thus coatings have now become widespread and a very important technique for adding value to the efficiency (protection and durability) of a material. Surface coating is an economical method used for the production of tools, machine components and materials that require the desired surface properties such as wear resistance, corrosion and erosion [3]. The most common surface coating methods/technologies include: Vapour deposition (VD), Chemical vapour deposition (CVD), Electro deposition coating (EDC) and Thermal spraying (TS). In VD method, the material in vapour state condenses to form a solid material. It is mostly used to form infiltrate fabric to form composite materials, films and fibers [4]. In CVD, the deposition involves homogeneous/heterogeneous reactions that occur on the heated surface leading to uniform film formation with good adhesion and reproducibility [5-6]. EDC provides protection by deposition of metallic ions and thereby enhances the corrosion properties of the substrate [7-8]. In TS, the material is heated and propelled onto the surface as droplets. The sprayed droplets then cool and build up into a laminar structure forming the TS coating [9]. TS covers high surface area of a substrate and the materials used as feedstock includes a wide range i.e. refractory metals, ceramics, plastics, composites etc. The two important components that make up the surface coating are Liquid coating and Powder coating. Liquid coatings are organic based materials comprising of resins with combination of solvent and water based carriers to ensure satisfactory adhesion, wetting and curing properties [10]. Liquid coatings have been the dominant form of liquid finish applied to metal parts over the years, but more interest has been directed to waterborne and high-solids coatings, which release a minimal amount of volatile organic compounds (VOCs) during application when compared to traditional solvent borne coatings [11].

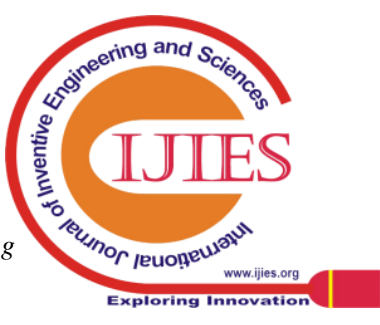


Powder coating applied as a dry powder, it then forms into a heated film. The process of application makes use of solid binder and pigment. The solid binder melts when hot, binds the pigment and results in a coating of pigment after cooling [12]. The advantages of powder coatings over liquid coatings include the absence of volatile organic content, elimination of hazardous waste, environmental attributes, high performance etc. Consequently, powder coatings enjoy high growth, as process industries explore ways to meet environmental and performance challenges. There are two major coating systems based on the resin of powder coatings i.e. Thermosetting \& Thermoplastic. Thermosetting powder coatings consist of resin, heat-setting agent, pigment, filler and additives. Thermoplastic powder coating is made of resin, dye, filler, plasticizer, and stabilizer [13-14]. Powder coatings have very high flow ability because of micro-fine particles that makes honest construct requirements and also the coating will have specific functions after adding corresponding modification substances like additives [12].

In India, the powder coatings market is anticipated to reach $\$ 1,508.2$ million by 2025 , registering a CAGR of $6.6 \%$ from 2018 to 2025. The Indian market is driven by a rise in demand from applications such as automotive, general industrial, furniture, and others. The market size is expanding at a significant pace owing to rising foreign direct investments (FDI) due to make in India scheme. With regards to resin type, the thermoset segment has occupied the highest share $(93.7 \%)$ in the overall market (due to rise in demand from automotive industry) and is expected to continue its dominance throughout the analysis period. Based on coating method, owing to high transfer efficiency and less overspray, Electrostatic spray method is dominating Indian market (adopted across various end user industries).

The research progress on surface coatings, specifically powder coatings have been substantiated with the work done by various researchers [15-19]. The gaps between the existing literature and our research work were identified and categorized into two area's:

(1). Systematic comparision between polymer powder coating with conventional liquid-based coatings on different conventional materials using economical additives has not been studied.

(2). Elaborative comparision of coatings strength or durability using various characterization techniques were not explored.

Therefore the hypothesis of this research work includes, the significance of powder coatings in the evolution of existing conventional surface coating technology under the influence of additive for their practical applications in processing industries. Based on the hypothesis, the two main objectives of the current research study are:

(1). Scientific comparison between polymer powder coating with liquid-based coatings.

(2). A comparison between the polymer coating with additive filled and with normal polymer coating.

The major future scope of the current experimental study is to promote the use of environmentally friendly coating materials. And powder coatings is a key consequence of this trend (both in decorative and protective coatings markets) as it provides good corrosion resistance and gives adhesion with no pretreatment of conversion coating.

\section{MATERIALS AND METHODS}

\section{A. Materials}

The Conventional \& commercial raw materials (Fig. 1) used in this study were threefold of Cement planks (17 x $10 \mathrm{x}$ $\left.1.7 \mathrm{~cm}^{3}\right)$, Wooden blocks (15 x $\left.4.3 \times 2.9 \mathrm{~cm}^{3}\right)$ and metal square panels that includes Copper $\left(7.4 \times 10.4 \times 0.1 \mathrm{~cm}^{3}\right)$, Aluminium (6.9 x $\left.10.2 \times 0.1 \mathrm{~cm}^{3}\right)$, Galvanized iron (7.2 x 10.2 $\left.\mathrm{x} 0.1 \mathrm{~cm}^{3}\right)$, Brass $\left(7.2 \times 10.7 \times 0.1 \mathrm{~cm}^{3}\right)$. The materials required for coating are conventional-liquid paint, electrostatic powder $(40-60 \mu \mathrm{m})$, research-grade graphene powder (additive) and emery paper. The apparatus and testing tools required for the experimentation were digital weighing balance, drying oven, paint booth, compressed air unit, powder coating gun, powder storage container, scratch hardness tester, thickness tester, and impact resistance tester. Surgical gloves and face masks were mandatory protective gear required for safe application of the paint.
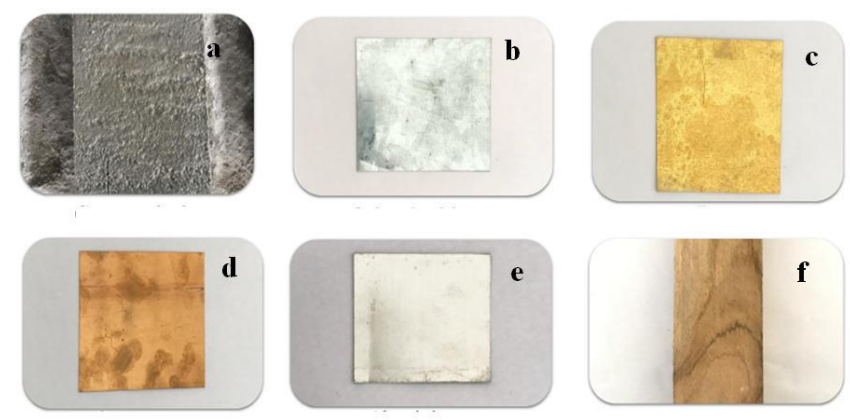

Fig. 1. Conventional \& commercial raw materials used for this research study. (a). Cement plank, (b). Galvanized iron,

(c). Brass, (d). Copper, (e). Aluminium, (f). Wooden block.

\section{B. Methods}

\section{(1). Surface Preparation:}

Surface preparation is an essential step for guaranteeing the quality and shelf life of coated materials. Prior to coating application, the surface needs to be thoroughly cleaned and prepared for final coating. Any rust, oil, dirt, moisture, or other contamination might result in poor adherence of paint and also affect the aesthetic look and life of the paint.

(a). All the metals selected were checked to estimate the quality of the material. The metal panels were dry scuffed using emery paper (Fig. 2).

(b). After scuffing, the respective sample materials were then dipped (for 20 mins) in 3 in 1 chemical (zinc phosphate chemical and magnesium phosphate) for primer coat and dried in hot air oven at $25-30^{\circ} \mathrm{C}$ for $10-15$ mins.

(c). A passivation layer was created that prevents oxidation and enhances the adhesion of the subsequent coating. Materials like wooden block and cement plank employ different preparation methods.

(d). The uneven wood on the block is chiselled out for smoothening the surface and a primer coat was applied before the application of paint. Whereas, cement

planks were cured for 7-14 days followed by the application of a primer coat prior coating.

Published By:
Blue Eyes Intelligence Engineering \& Sciences Publication (C) Copyright: All rights reserved. 


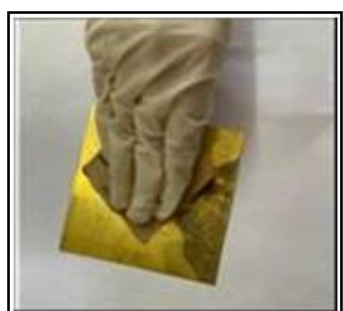

Fig. 2. Dry scuffing of the materials/metal panels using emery paper.

\section{(2). Surface coating process:}

The coating processes involved in the current experimental study were: (i). liquid coating, (ii). powder coating and (iii). powder coating under the influence of additive (graphene). Coatings have remarkable porosity and corrosion performance is improved if the number of layers is increased as it improves the adhesion/sealing of the film.

(i). Liquid coating process: Conventional-liquid paint was used for coating the selected raw materials.

(a). The panels were placed in the paint booth using V-type hooks. The liquid paint was sprayed horizontally (from top to bottom maintaining $25 \mathrm{~cm}$ distance from the material) onto the panel using spray gun (Fig. 3).

(b). It was ensured that the paint spreads uniformly on the surface. The coated materials were then cured rapidly by drying (at $25-30^{\circ} \mathrm{C}$ for $10-15$ mins) in hot air oven.

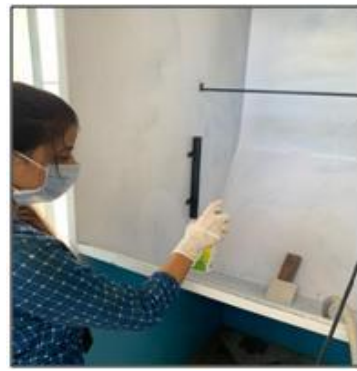

Fig. 3. Liquid paint used for coating the selected raw materials using spray gun.

(ii). Powder coating process (dry finishing process):

(a). In this process, electrostatically charged powder was used and sprayed onto the selected material.

(b). The analyzed electrostatic powder particle size is $40-60 \mu \mathrm{m}$ in $1 \mathrm{~kg}$ of powder to accept the electrostatic effect which was loaded in the storage container that was connected to powder coating gun and compressed air unit.

(c). The powder particles will be positively charged at the gun tip due to highly negative potential electrodes. The air around the gun tip becomes conductive and a corona field is formed.

(d). A loaded powder mist was formed in the area between the gun tip and the grounded work piece. The electrical field ensures the trajectory of the powder mist from the gun tip to the workpiece.

(e). This ensured that the powder was deposited very efficiently on the workpiece. The compressed air was blown through the powder reservoir resulting in a fluidized powder movement.

(f). The raw material was placed in the paint booth using $\mathrm{V}$-neck holder and powder coating was done using the electrostatic gun (Fig. 4). (g). The powder was transmitted through an electrostatic process which causes the powder particles to stick to the chosen surface and ensures proper adhesion due to charged volts of electrostatic energy.

(h). Finally, the powder coated material was cured (in the drying oven $\left(180^{\circ} \mathrm{C}\right.$ for $\left.15-20 \mathrm{~min}\right)$. Thermal bonds are produced between the powder particles during the curing process which results in a smooth and hard finish of the powder-coated materials.

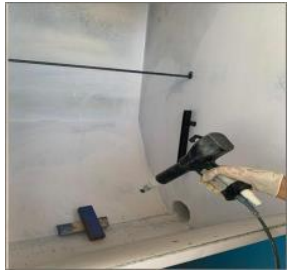

Fig. 4. Powder coating of selected raw materials using the electrostatic gun.

(iii). Powder coating process under the influence of additive (graphene):

(a). An additive was added to the powder coating to improve its additional properties and performance.

(b). Graphene (research grade powder) was selected as an additive for this experimental study, due to its excellent mechanical strength, along with its exceptional electrical and thermal conductive properties, that makes it attractive for a wide range of applications.

(c). Graphene serves as a very good barrier against both oxidation and chemical attack from immersion in salty, acidic water. As it acts as a reinforcing material in resin systems, graphene may actually enhance the adhesion of the coating to the substrate [20].

(d). The coating process is similar/ parallel to the powder coating process. For coating process, 0.03:1 ratio [21] i.e. mixture of 6 gm of graphene powder along with 200 gm of electrostatic powder was used (Fig. 5).

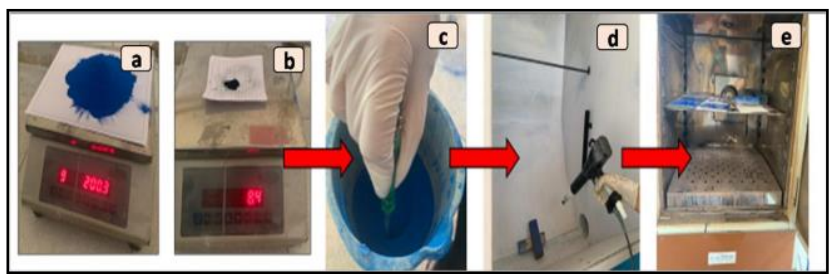

Fig. 5. (a). Electrostatic powder, (b). Additive (graphene), (c). Mixing of powder and additive, (d). Application of powder coat onto the substrate, (e). Curing process of coated surfaces.

\section{Testing methods}

The coated (liquid, powder \& powder with additive) materials should pass the testing methods which will enable them to exhibit certain qualitative and quantitative properties. They act as a quality control measure to ensure that coated products meet specified properties and provide data for lifetime prediction and performance by evaluation under certain conditions.
Plue Eyes Intelligence Engineering \& Sciences Publication (C) Copyright: All rights reserved.

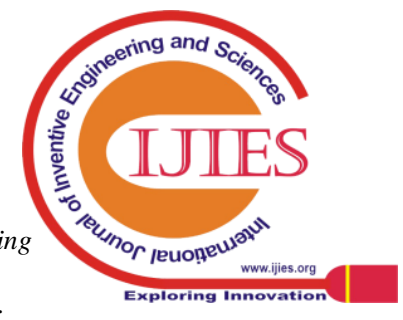


Different methods of testing are available to understand the behaviour of coating on a fundamental level. For this study, the ISO standard characterization techniques deployed on the coated surfaces of conventional materials chosen were: Thickness test, Impact resistance test, Adhesion test and Scratch hardness test (Fig. 6).
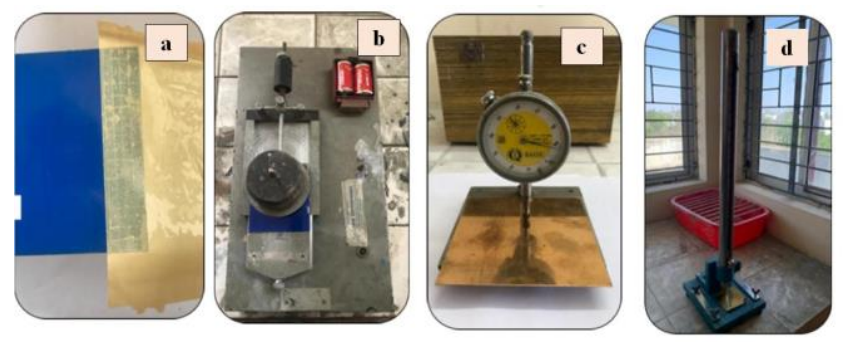

Fig. 6. The ISO standard characterization techniques deployed on the coated surfaces of conventional materials. (a). Adhesion test, (b). Scratch hardness test, (c). Thickness test, (e). Impact resistance test.

\section{i. Thickness test [ISO 2808:2019(en)]:}

This method was used for measuring the thickness of coating on the material surface. The thickness tester instrument measures the thickness of powder coatings and liquid coatings on variety of selected substrates before and after coating. Thickness test was performed by placing the metal panel under film thickness tester. The tester translates the thickness of the coating on the substrate into the digitally read test results. The thickness was measured at three random points and the average value was taken as the final thickness of the film.

\section{ii. Impact resistance test [ISO 6272-1:2011(en)]:}

This test was used to characterize the quality, crack formation, adhesion, elasticity and breaking strength of the coatings. The sample metal panel was firmly fixed at the bottom end of the tester. A standard amount of weight (metal ball: $0.6 \mathrm{~kg}$ ) was dropped from a height of $90-100 \mathrm{cms}$ to strike the coated material. A bulge was formed on the surface of the coated material due to the impact of metal ball with a hemispherical end. The bulge was the basis to determine the quality of the coating by visually checking for elongation, peeling and cracking of the coating.

\section{iii. Adhesion test [ISO 2409:2013(en)]:}

In coating industries, paint adhesion testing method determines whether the coating applied has adhered firmly onto the surface of the materials to which they are applied and also provides a visual assessment of the quality of the bond on the coated surface. This test was performed by making a crosshatch pattern with a needle through the coated panel. An adhesive tape was taped over the crosshatch cut and was removed by pulling it off with a considerable force, rapidly. The crosshatch cut area was inspected to see if any coating was removed and was assessed visually on a scale of 0 to 5 .

\section{iv. Scratch hardness test [ISO 1518-1:2011]:}

This test was used to find the strength of the paint coated on the surface of the material. The coated panel was placed firmly within the scratch hardness tester. A single specified load was added to the tester and gradually increasing the load (weights used for testing: 500 gm, 1000 gm, 1500 gm, 2000 gm \& 2500 gm), successively to determine the minimum load at which the coating can be spiked by applying the drag force. The scratches from different specific loads were noted down based on visual evaluation.

\section{RESULTS AND DISCUSSIONS}

\section{i. Liquid vs. Powder coating:}

Surface finishing is essential for the practical use of reactive metals (eg: ductile iron). When these metals are left unprotected, they undergo oxidization to form rust. This implies that colourful exteriors aren't just decorative-they are functional barriers that prevent corrosion.

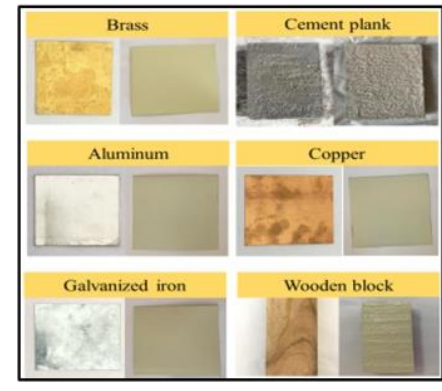

Liquid-based coatings

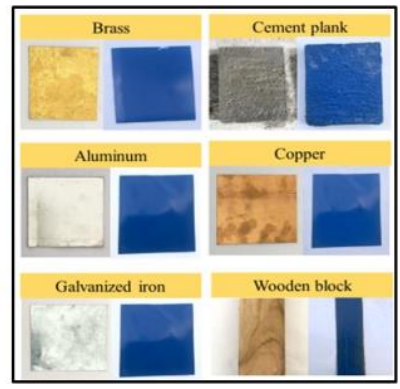

Powder-based coatings

\section{Fig. 7. Liquid-based and powder-based coatings on the selected sample materials.}

As shown in Figure. 7, the surface finishing on conventional materials by powder coating develops a thick, adhesive finish. The panel acquired a high glossy, smooth-finished look whereas the liquid-coated materials produced a comparatively thin coating and the paint slightly dripped and sagged on the substrate surface. Liquid coating leaves trace marks and under-applied in certain areas, over-applied in other areas, and drippy along points. It requires multiple coats to obtain a smooth, even finish with spray paint. But, powder coats produced consistently smooth and solid surface with no trace of application marks. It can also be cured quickly, resulting in faster production cycles.

The thickness of a paint film on a surface is of great industrial importance. It gives the surface., good adhesion, good gloss and strength. Thickness range as defined by the manufacturers is, essential to optimize the level of protection available from the coating.

Too little coating might leave some of the substrates surface still exposed and might leave the substrate vulnerable. The issue with excessive thickness includes sagging, in which the coating sags down due to gravity while still wet, leaving an unsightly uneven surface, which could lead to other parts of the surface being insufficiently thick [22]. The experimental results of thickness test results were presented in (Table I).

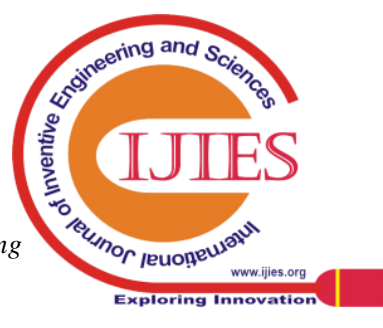


Table- I: The experimental results of thickness test for (a). Liquid-coated and (b). Powder-coated materials. (a). Liquid coating

\begin{tabular}{|c|c|c|c|}
\hline S. No & Material & $\begin{array}{c}\text { Thickness } \\
\text { (before) }\end{array}$ & $\begin{array}{c}\text { Thickness } \\
\text { (after) }\end{array}$ \\
\hline 1 & Brass & $62.6 \mathrm{~mm}$ & $67.6 \mathrm{~mm}$ \\
\hline 2 & Galvanized iron & $68.3 \mathrm{~mm}$ & $73.3 \mathrm{~mm}$ \\
\hline 3 & Copper & $65.6 \mathrm{~mm}$ & $70.6 \mathrm{~mm}$ \\
\hline 4 & Aluminium & $123 \mathrm{~mm}$ & $128 \mathrm{~mm}$ \\
\hline
\end{tabular}

\begin{tabular}{|c|c|c|c|}
\hline \multicolumn{4}{|c|}{ (b). Powder coating } \\
\hline S. No & Material & $\begin{array}{c}\text { Thickness } \\
\text { (before) }\end{array}$ & $\begin{array}{c}\text { Thickness } \\
\text { (after) }\end{array}$ \\
\hline 1 & Brass & $67 \mathrm{~mm}$ & $72 \mathrm{~mm}$ \\
\hline 2 & Galvanized iron & $58.4 \mathrm{~mm}$ & $63.4 \mathrm{~mm}$ \\
\hline 3 & Copper & $98.5 \mathrm{~mm}$ & $103.5 \mathrm{~mm}$ \\
\hline 4 & Aluminium & $135 \mathrm{~mm}$ & $140.3 \mathrm{~mm}$ \\
\hline
\end{tabular}

Thickness measurements of powder and liquid coat are taken before and after curing. From the attained quantitative results, it was observed that powder coating has achieved a thicker and more consistent finish (without running and sagging) than liquid paints for all the selected raw materials. Powder coatings can be applied over a wide range of thickness depending on interior or exterior applications. Accurate thickness of coating helps to avoid stripping and re-coating which can cause problems with coating integrity and adhesion.

Table- II: The experimental results of impact resistance test for liquid-coated and powder-coated materials.

\begin{tabular}{|c|c|c|c|}
\hline \multicolumn{4}{|c|}{ Condition of the coated material } \\
\hline S. No & Material & Liquid coating & Powder coating \\
\hline 1 & Brass & Bad & Excellent \\
\hline 2 & Galvanized iron & Worst & Worst \\
\hline 3 & Copper & Average & Average \\
\hline 4 & Aluminium & Average & Excellent \\
\hline 5 & Wooden block & Average & Excellent \\
\hline
\end{tabular}

The ability to withstand mechanical impacts is of vital importance for the protective function of coating materials. The concept of impact resistance refers to the application of kinetic energy at a point and the effect of this on the adhesion of the coating. Impact resistance test gives importance and durability to the paint film. This test scrutinizes the performance of liquid-based and powder-based coatings on the selected sample materials for their ability to resist cracking caused by impact [23]. The results are summarized in Table II. From the test results it was observed that powder coated materials have displayed better toughness, considerable resistance to cracking and other wear in comparision with liquid paints. This is because of the thermal bonding it undergoes during curing, and because it is applied in much thicker layers [12]. This parameter is crucial for coating outdoor products. Since the degree of damages to the coated materials caused by mechanical impact will be the determining factor for the useful lifetime of a coating system, therefore it is equally important to consider mechanical properties when comparing performance properties of coated materials.

As shown in Figure 8, galvanized iron failed the test by visible cracking and peeling of coated film for both powder based and liquid based coatings. This could be due to its low cohesive nature. Whereas, copper coated films showed mediocre performance with slight peeling of the film from the substrates. The total sum of stress exceeded the strength of the coating which in turn causes the film to crack. Liquid-coated materials like copper, wooden block and aluminium delivered an average performance with scant peeling of film from the substrates which displays the low quality of paint and fatigue resistance to deformity caused by impact. The powder based coated applied on brass showed much higher impact resistance than the liquid-paint based coating applied on the same material. Powder based coated metal panels like brass, aluminium and wooden block demonstrated very attractive performance characteristics compared to the other tested coatings. It exhibited no sign of cracking and peeling of the film from the substrate. Resulting in higher strength, better flexibility and improved crack resistance especially for excess film thickness. The cohesive nature is of concern because it adds to the external stresses (e.g. thermal stress or deformation of the substrate), when the coating is exposed to during the service. Further evaluation is done by performing tape-pull test to determine the amount of coating removed.

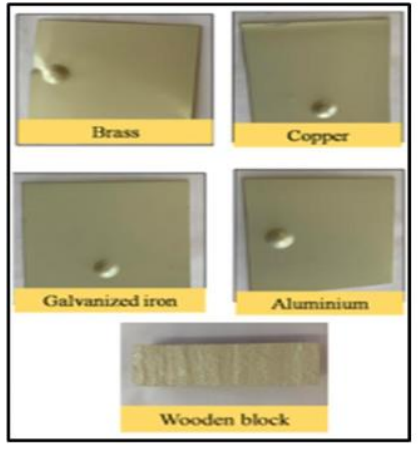

Liquid-based coatings

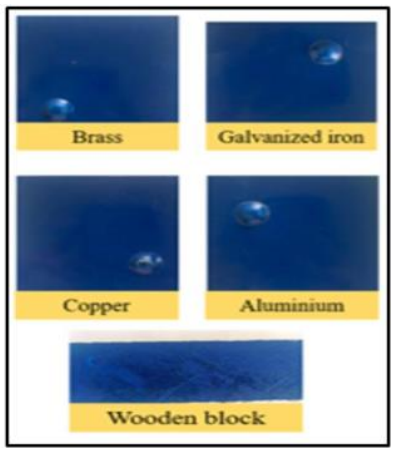

Powder-based coatings
Fig. 8. Impact resistance test on liquid-coated and powder-coated panels.

The two basic properties of paint which depend on durability and performance coatings are: cohesion and adhesion. Cohesion is the inner strength of a material, and it is determined by the strength of molecular forces in the bulk. Adhesion is the strength of the bonds forming between one material and the another. Adhesive failure can be blister forming at the interface or removal

of the paint film at the interface

etc [24]. For a long-lasting protective coating, both cohesion and adhesion are required. A coating with "good" adhesion to the substrate will have superior mechanical properties and corrosion resistance and will outperform a coating with "poor" adhesion.

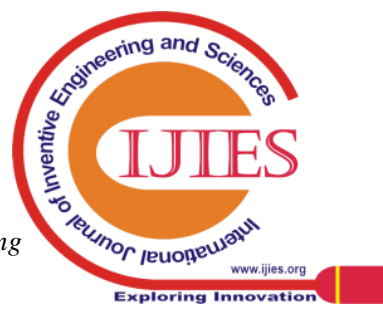


The adhesive strengths and visual assessment of powder-coating and liquid coating to various sample materials which were measured by adhesive tape testing are presented in Figure. 9 and Table III. In order to get a better evaluation of the adhesive strengths of the coated material a scoring system was used. The coatings adhesive properties were ranked on a scale $0-5$. Weak adhesion appears on the interface of liquid-coated and powder-coated copper metal panels. This paint adhesion failure on copper might be due to late application of paint after cleaning which would have caused delamination of the oxide film from the liquid coated metal and for powder-coated copper sample, some moisture that bled out during curing would have caused of adhesion loss over a small area of the panel. Liquid coated materials slightly exfoliated paint film from the interface of the samples resulting in low adhesion. This failure might be due to low quality paint lacking flexibility or thin coats which are less adhesive. On the other hand, most of the powder coated film on the sample materials like brass, galvanized iron, aluminium and wooden block are not exfoliated from the metal panels, indicating strong adhesion. Especially brass sample has shown good quality of the bond with the coated surface. Overall it can be stated that, good adhesion and cohesion properties were observed for all electrostatic powder coated metal panels in comparision with liquid coatings.

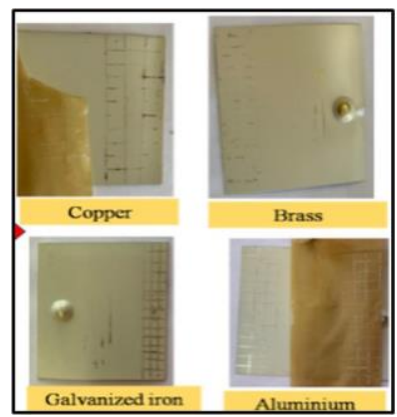

Liquid-based coatings

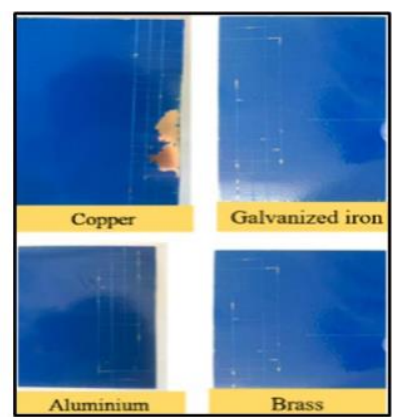

Powder-based coatings
Fig. 9. Adhesion test performed on liquid-coated and powder-coated panels.

Table- III: The experimental results of adhesion test for liquid-coated and powder-coated materials.

\begin{tabular}{|c|c|c|c|}
\hline \multicolumn{4}{|c|}{ Condition and assessment of the coated material } \\
\hline S. No & Material & $\begin{array}{c}\text { Liquid } \\
\text { coating }\end{array}$ & $\begin{array}{c}\text { Powder } \\
\text { coating }\end{array}$ \\
\hline 1 & Brass & Average - 3 & Good - 4.5 \\
\hline 2 & $\begin{array}{c}\text { Galvanized } \\
\text { iron }\end{array}$ & Bad - 2.5 & Good - 4 \\
\hline 3 & Copper & Worst - 1 & Worst - 1.5 \\
\hline 4 & Aluminium & Worst - 1.5 & Good - 4 \\
\hline 5 & $\begin{array}{c}\text { Wooden } \\
\text { block }\end{array}$ & Average - 3 & Average - 3 \\
\hline
\end{tabular}

*Excellent - 4.5-5, Good - 4-4.5, Average - 3-4, Bad - 1.5-3, Worst - 0-1.5

A scratch hardness test is often used for making a comparative evaluation of coatings performance. This test is evaluated by refined visual observation. Figure. 10 and Table IV illustrates the typical results of scratch hardness test on various sample metal panels.

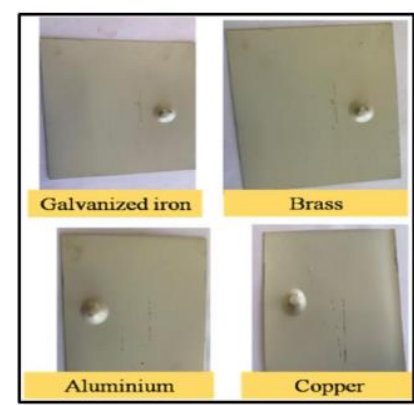

Liquid-based coatings

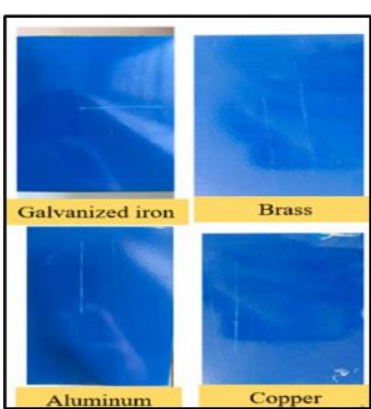

Powder-based coatings

Fig. 10. Scratch hardness test performed on liquid-coated and powder-coated panels.

At small load like 500 gm, no scratches were observed on both the coated metal panels showing good scratch resistance. 1500

As the load progressively kept increasing i.e. 1000 gm,

gm and 2000 gm, mild scratches were noticeable on liquid-coated substrates whereas powder-coated metal panels have shown a greater resistance to scratch damage.

The noticeable scratches on the liquid-coated samples are mainly be due to thin coating, low adhesion and the quality of the paint applied on the sample [25]. When liquid-coated samples were subjected to high load like 2500 gm, deep scratches were spotted causing a revealing base. The friction between the sharp object and the paint caused a substantial increase of temperature in the surface of the film and thus, mark is easily created on the liquid-coated panels. In liquid-coated aluminium panel, deep groove was created in the coating which lacks toughness for a good scratch resistance. However, when powder coated metal panels were subjected to high loads like $2000 \mathrm{gm}$ and 2500 gm, mild scratches were spotted whereas material like brass had no scratches indicating good strength, high cohesive and adhesive nature of powder coated surface.

Table- IV: The results of scratch hardness test for liquid-coated and powder-coated materials.

\begin{tabular}{|l|c|c|c|c|c|}
\hline $\begin{array}{c}\text { Liquid } \\
\text { coated } \\
\text { Material }\end{array}$ & $\mathbf{5 0 0} \mathbf{g m}$ & $\mathbf{1 0 0 0} \mathbf{g m}$ & $\mathbf{1 5 0 0} \mathbf{g m}$ & $\begin{array}{c}\mathbf{2 0 0 0} \\
\mathbf{g m}\end{array}$ & $\begin{array}{c}\mathbf{2 5 0 0} \\
\mathbf{g m}\end{array}$ \\
\hline Brass & $\begin{array}{c}\text { No } \\
\text { scratch }\end{array}$ & $\begin{array}{c}\text { No } \\
\text { scratch }\end{array}$ & $\begin{array}{c}\text { No } \\
\text { scratch }\end{array}$ & $\begin{array}{c}\text { Mild } \\
\text { Scratch }\end{array}$ & $\begin{array}{c}\text { Deep } \\
\text { Scratch }\end{array}$ \\
\hline $\begin{array}{l}\text { Galvanized } \\
\text { iron }\end{array}$ & $\begin{array}{c}\text { No } \\
\text { scratch }\end{array}$ & $\begin{array}{c}\text { No } \\
\text { scratch }\end{array}$ & $\begin{array}{c}\text { No } \\
\text { Scratch }\end{array}$ & $\begin{array}{c}\text { Mild } \\
\text { Scratch }\end{array}$ & $\begin{array}{c}\text { Deep } \\
\text { Scratch }\end{array}$ \\
\hline Copper & $\begin{array}{c}\text { No } \\
\text { scratch }\end{array}$ & $\begin{array}{c}\text { Mild } \\
\text { Scratch }\end{array}$ & $\begin{array}{c}\text { Mild } \\
\text { Scratch }\end{array}$ & $\begin{array}{c}\text { Mild } \\
\text { scratch }\end{array}$ & $\begin{array}{c}\text { Deep } \\
\text { Scratch }\end{array}$ \\
\hline Aluminium & $\begin{array}{c}\text { No } \\
\text { scratch }\end{array}$ & $\begin{array}{c}\text { Mild } \\
\text { Scratch }\end{array}$ & $\begin{array}{c}\text { Mild } \\
\text { Scratch }\end{array}$ & $\begin{array}{c}\text { Deep } \\
\text { Scratch }\end{array}$ & $\begin{array}{c}\text { Deep } \\
\text { Scratch }\end{array}$ \\
\hline
\end{tabular}

\begin{tabular}{|l|c|c|c|c|c|}
\hline $\begin{array}{c}\text { Powder } \\
\text { coated } \\
\text { Material }\end{array}$ & $\mathbf{5 0 0}$ gm & $\mathbf{1 0 0 0}$ gm & $\mathbf{1 5 0 0} \mathbf{g m}$ & $\begin{array}{c}\mathbf{2 0 0 0} \\
\mathbf{g m}\end{array}$ & $\begin{array}{c}\mathbf{2 5 0 0} \\
\mathbf{g m}\end{array}$ \\
\hline Brass & $\begin{array}{c}\text { No } \\
\text { scratch }\end{array}$ & $\begin{array}{c}\text { No } \\
\text { scratch }\end{array}$ & $\begin{array}{c}\text { No } \\
\text { scratch }\end{array}$ & $\begin{array}{c}\text { No } \\
\text { scratch }\end{array}$ & $\begin{array}{c}\text { No } \\
\text { scratch }\end{array}$ \\
\hline $\begin{array}{l}\text { Galvanized } \\
\text { iron }\end{array}$ & $\begin{array}{c}\text { No } \\
\text { scratch }\end{array}$ & $\begin{array}{c}\text { No } \\
\text { scratch }\end{array}$ & $\begin{array}{c}\text { No } \\
\text { scratch }\end{array}$ & $\begin{array}{c}\text { Mild } \\
\text { scratch }\end{array}$ & $\begin{array}{c}\text { Mild } \\
\text { scratch }\end{array}$ \\
\hline Copper & $\begin{array}{c}\text { No } \\
\text { scratch }\end{array}$ & $\begin{array}{c}\text { No } \\
\text { scratch }\end{array}$ & $\begin{array}{c}\text { No } \\
\text { scratch }\end{array}$ & $\begin{array}{c}\text { Mild } \\
\text { scratch }\end{array}$ & $\begin{array}{c}\text { Deep } \\
\text { Scratch }\end{array}$ \\
\hline Aluminium & $\begin{array}{c}\text { No } \\
\text { scratch }\end{array}$ & $\begin{array}{c}\text { No } \\
\text { scratch }\end{array}$ & $\begin{array}{c}\text { No } \\
\text { scratch }\end{array}$ & $\begin{array}{c}\text { Mild } \\
\text { scratch }\end{array}$ & $\begin{array}{c}\text { Mild } \\
\text { scratch }\end{array}$ \\
\hline
\end{tabular}

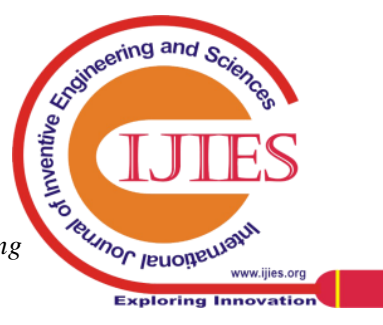


ii. Powder coating vs. Powder coating with additive (graphene):

The high performance of powder coatings is further increased by the use of additives. Additives are designed to improve properties such as prevention of discoloration during powder coating, curing, ease of spraying the powder onto the substrate, enhanced durability of the coating and improved corrosion resistance [20]. In this research work graphene was used as additive. Impressive thermal, electrical, optical, and mechanical properties, high chemical inertness, extreme strength and easy shear capability on its tightly packed and atomically smooth surface are some of the major favourable attributes of graphene as additive. Ultrathin even with multi layers makes graphene stand out as additive [26]. The average thickness maintained for powder coated panels is 4-5 $\mathrm{mm}$. Thickness of paint film for powder coating with additive is slightly higher by $1 \mathrm{~mm}$ due to increase of graphene particle size (Table V). Hence the average thickness is 5-6 $\mathrm{mm}$.

Table- V: The experimental results of thickness test for graphene based powder coating.

\begin{tabular}{|c|c|c|c|}
\hline \multicolumn{4}{|c|}{ Powder coating with additive } \\
\hline S. No & Material & $\begin{array}{c}\text { Thickness } \\
\text { (before) }\end{array}$ & $\begin{array}{c}\text { Thickness } \\
\text { (after) }\end{array}$ \\
\hline 1 & Brass & $67 \mathrm{~mm}$ & $73.3 \mathrm{~mm}$ \\
\hline 2 & Galvanized iron & $50 \mathrm{~mm}$ & $56 \mathrm{~mm}$ \\
\hline 3 & Copper & $47 \mathrm{~mm}$ & $53 \mathrm{~mm}$ \\
\hline 4 & Aluminium & $143 \mathrm{~mm}$ & $150 \mathrm{~mm}$ \\
\hline
\end{tabular}

For brass substrate, graphene based powder coating (GPC) has endured scratch hardness test beyond 2500 gms load force compared to simple powder coated (SPC) brass sample Figure. 11 and Table VI.

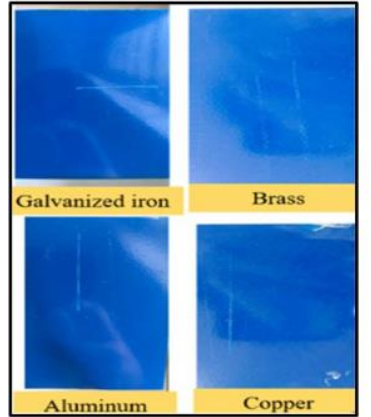

SPC panels

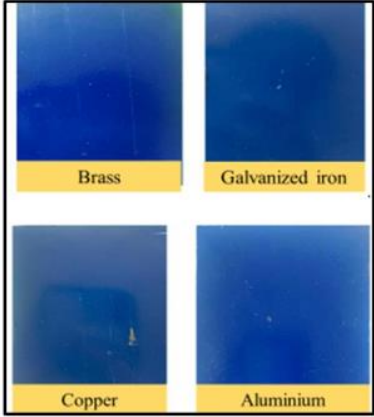

GPC panels
Fig. 11. Scratch hardness test performed on GPC and SPC panels.

Table- VI: The experimental results of scratch hardness test for SPC and GPC materials.

\begin{tabular}{|l|c|c|c|c|c|}
\hline $\begin{array}{c}\text { SPC } \\
\text { Material }\end{array}$ & $\mathbf{5 0 0} \mathbf{~ g m}$ & $\mathbf{1 0 0 0} \mathbf{g m}$ & $\mathbf{1 5 0 0} \mathbf{g m}$ & $\begin{array}{c}\mathbf{2 0 0 0} \\
\text { gm }\end{array}$ & $\begin{array}{c}\mathbf{2 5 0 0} \\
\mathbf{g m}\end{array}$ \\
\hline Brass & $\begin{array}{c}\text { No } \\
\text { scratch }\end{array}$ & $\begin{array}{c}\text { No } \\
\text { scratch }\end{array}$ & $\begin{array}{c}\text { No } \\
\text { scratch }\end{array}$ & $\begin{array}{c}\text { No } \\
\text { scratch }\end{array}$ & $\begin{array}{c}\text { No } \\
\text { scratch }\end{array}$ \\
\hline $\begin{array}{l}\text { Galvanized } \\
\text { iron }\end{array}$ & $\begin{array}{c}\text { No } \\
\text { scratch }\end{array}$ & $\begin{array}{c}\text { No } \\
\text { scratch }\end{array}$ & $\begin{array}{c}\text { No } \\
\text { scratch }\end{array}$ & $\begin{array}{c}\text { Mild } \\
\text { scratch }\end{array}$ & $\begin{array}{c}\text { Mild } \\
\text { scratch }\end{array}$ \\
\hline Copper & $\begin{array}{c}\text { No } \\
\text { scratch }\end{array}$ & $\begin{array}{c}\text { No } \\
\text { scratch }\end{array}$ & $\begin{array}{c}\text { No } \\
\text { scratch }\end{array}$ & $\begin{array}{c}\text { Mild } \\
\text { scratch }\end{array}$ & $\begin{array}{c}\text { Deep } \\
\text { scratch }\end{array}$ \\
\hline
\end{tabular}

\begin{tabular}{|c|c|c|c|c|c|}
\hline Aluminium & $\begin{array}{c}\text { No } \\
\text { scratch }\end{array}$ & $\begin{array}{c}\text { No } \\
\text { scratch }\end{array}$ & $\begin{array}{c}\text { No } \\
\text { scratch }\end{array}$ & $\begin{array}{c}\text { Mild } \\
\text { scratch }\end{array}$ & $\begin{array}{c}\text { Mild } \\
\text { scratch }\end{array}$ \\
\hline
\end{tabular}

\begin{tabular}{|l|c|c|c|c|c|}
\hline $\begin{array}{c}\text { GPC } \\
\text { Material }\end{array}$ & $\mathbf{5 0 0}$ gm & $\mathbf{1 0 0 0}$ gm & $\mathbf{1 5 0 0}$ gm & $\begin{array}{c}\mathbf{2 0 0 0} \\
\mathbf{g m}\end{array}$ & $\begin{array}{c}\mathbf{2 5 0 0} \\
\mathbf{g m}\end{array}$ \\
\hline Brass & $\begin{array}{c}\text { No } \\
\text { scratch }\end{array}$ & $\begin{array}{c}\text { No } \\
\text { scratch }\end{array}$ & $\begin{array}{c}\text { No } \\
\text { scratch }\end{array}$ & $\begin{array}{c}\text { No } \\
\text { scratch }\end{array}$ & $\begin{array}{c}\text { No } \\
\text { scratch }\end{array}$ \\
\hline $\begin{array}{l}\text { Galvanized } \\
\text { iron }\end{array}$ & $\begin{array}{c}\text { No } \\
\text { scratch }\end{array}$ & $\begin{array}{c}\text { No } \\
\text { scratch }\end{array}$ & $\begin{array}{c}\text { No } \\
\text { scratch }\end{array}$ & $\begin{array}{c}\text { No } \\
\text { scratch }\end{array}$ & $\begin{array}{c}\text { No } \\
\text { scratch }\end{array}$ \\
\hline Copper & $\begin{array}{c}\text { No } \\
\text { scratch }\end{array}$ & $\begin{array}{c}\text { No } \\
\text { scratch }\end{array}$ & $\begin{array}{c}\text { No } \\
\text { scratch }\end{array}$ & $\begin{array}{c}\text { Mild } \\
\text { scratch }\end{array}$ & $\begin{array}{c}\text { Mild } \\
\text { scratch }\end{array}$ \\
\hline Aluminium & $\begin{array}{c}\text { No } \\
\text { scratch }\end{array}$ & $\begin{array}{c}\text { No } \\
\text { scratch }\end{array}$ & $\begin{array}{c}\text { No } \\
\text { scratch }\end{array}$ & $\begin{array}{c}\text { No } \\
\text { scratch }\end{array}$ & $\begin{array}{c}\text { Mild } \\
\text { scratch }\end{array}$ \\
\hline
\end{tabular}

This indicates that graphene addition improved the performance of powder coating. Copper exhibited mild scratches under influence of 2000 gms load force for both SPC and GPC.

However, a prominent scratch was observed on the copper panel at 2500 gms in case of SPC. Similarly, mild scratch was observed in galvanized iron (GI) and aluminium after 2000 gms load force. All GPC panels have outperformed SPC panels except for copper, as this impact resistance test has revealed mild peeling of powder film Figure. 12 and Table VII. For GPC, surface pre-treatment is critical so as to withstand load dropped from a particular height. SPC panels of GI has failed to qualify this test as evident from the visible cracking of the paint film while has copper shown better results when compared to GI. The other painted panels performed better.
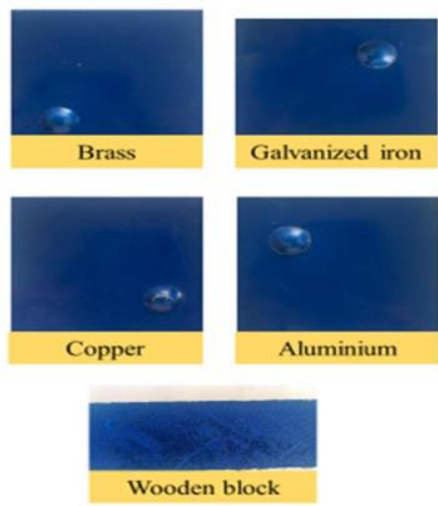

Fig. 12. Impact resistance test performed on GPC panels.

Table-VII: The experimental results of impact resistance test for SPC and GPC materials.

\begin{tabular}{|c|c|c|c|}
\hline \multicolumn{4}{|c|}{ Condition and assessment of the coated material } \\
\hline S. No & Material & SPC & GPC \\
\hline 1 & Brass & Excellent & Excellent \\
\hline 2 & Galvanized iron & Good & Excellent \\
\hline 3 & Copper & Average & Good \\
\hline 4 & Aluminium & Excellent & Excellent \\
\hline 5 & Wooden block & Excellent & Excellent \\
\hline
\end{tabular}

Published By:

Blue Eyes Intelligence Engineering

\& Sciences Publication

(C) Copyright: All rights reserved.

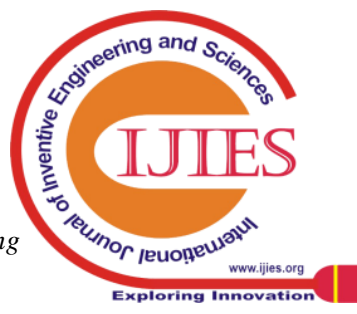




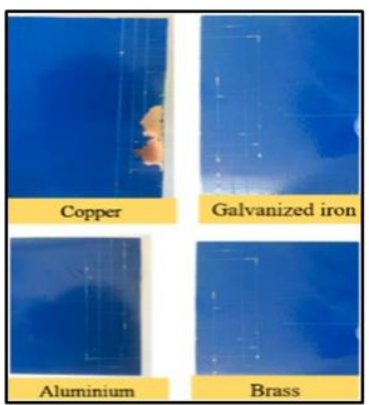

SPC panels

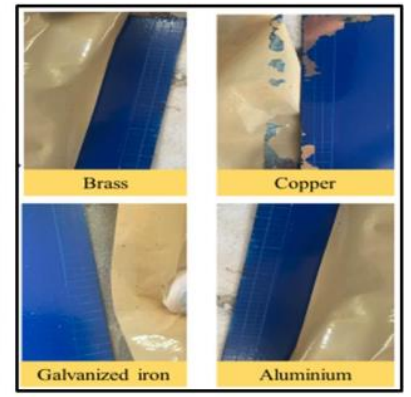

GPC panels
Fig. 13. Adhesion test performed on SPC and GPC panels.

In case of adhesion test, GPC has edged SPC in this test Figure. 13 and Table VIII. Brass has performed well. SPC copper panel has failed to qualify, along with GPC copper panel with limited performance. GI and aluminium exhibited same behaviour for both types of panels. Therefore it is observed that GPC adheres to panel, whereas SPC has low adhesion at the interface boundary layer.

Table-VIII: The experimental results of adhesion test for SPC and GPC materials.

\begin{tabular}{|c|c|c|c|}
\hline \multicolumn{4}{|c|}{ Condition and assessment of the coated material } \\
\hline S. No & Material & SPC & GPC \\
\hline 1 & Brass & Good-4.5 & Excellent-5 \\
\hline 2 & $\begin{array}{c}\text { Galvanized } \\
\text { iron }\end{array}$ & Good-4 & Good-4.5 \\
\hline 3 & Copper & Worst-1.5 & Average-3.5 \\
\hline 4 & Aluminium & Good-4 & Good-4.5 \\
\hline 5 & Wooden block & Average - 3 & Excellent - 5 \\
\hline
\end{tabular}

*Excellent - 4.5-5, Good - 4-4.5, Average - 3-4, Bad - 1.5-3, Worst - 0-1.5

\section{CONCLUSIONS}

1. A systematic comparison between two different surface coating techniques have been carried out to understand the mechanism of film formulation and also to determine the effect of the process and formulation variables on commercial raw materials (copper, aluminum, galvanized iron, brass, cement plank, wood block).

2. The test results have shown that, in the adhesion test, powder coated film on the sample materials are not exfoliated from the metal panels indicating strong adhesion, unlike liquid coated panels. In impact resistance test, it was observed that powder coated materials have displayed excellent resistance $\&$ better toughness to cracking and other wear in comparision with liquid paints. And in thickness test, it was observed that powder coating has achieved a thicker and more consistent finish than liquid paints for all the selected raw materials. etc.

3. The qualitative and quantitative test results obtained from characterization techniques using powder coating were promising as the values indicated good quality (high strength and good hardness) and durability (good surface resistance, high thickness) in comparison with liquid coating for all selected conventional raw materials.
3. Further studies were done in the combination of powder along with additive to enhance the quality of powder coated surface. In this aspect, graphene as additive in powder coating was used to evaluate/check the quality and durability of selected conventional materials.

4. From the attained experimental results, it was observed that addition of additive (graphene) in powder coat has improved characteristics (high strength) and quality (high gloss) to the powder coated materials i.e. SPC panels have failed to qualify impact resistance test as visible cracking of the paint film was observed when compared to GPC. In adhesion test, it is observed that GPC adheres to panel, whereas SPC has low adhesion at the interface boundary layer).

\section{ACKNOWLEDGMENT}

The authors thank CBIT management for extending their support and providing us with numerous facilities to carry on with the experimental work. Sincere thanks to Chemical Engineering department HOD, Dr. B. Sreedhara Rao and Dr. B.V.S. Rao, Assistant Professor, Mechanical Engg Dept for lending their support in smooth running of the experimentation. Also, heartfelt thanks to Technician Mr. Sathyanarayana for assisting in handling various equipments.

\section{REFERENCES}

1. Rao Sunil, Kumar Sumith, Palle Manasa, Sriharsha Pusuluri, A critical review on surface coatings for engineering materials, IJMET, vol. 7, 2016, pp. 80-85.

2. Salgueiro Azevedo M, Allély C, Ogle K, Volovitch P, Corrosion mechanisms of $\mathrm{Zn}(\mathrm{Mg}, \mathrm{Al})$ coated steel in accelerated tests and natural exposure: 1. The role of electrolyte composition in the nature of corrosion products and relative corrosion rate, Corrosion Science, vol. 90, 2015, pp. 472-481.

3. Vineet Shibe, Vikas Chawla, An overview of research work in surface coating, IJRMET, vol. 3, 2013, pp. 85-88.

4. Prengel H. G, Pfouts W. R, Santhanam A. T, State of the art in hard coatings for carbide cutting tools. Surface and Coatings Technology, vol. 102, 1998, pp. 183-190.

5. Nemani Kartik, Sojoudi Hossein, Barrier performance of CVD graphene films using a facile P3HT thin film optical transmission test, Journal of Nanomaterials, 2018, pp. 1-11, DOI: 10.1155/2018/9681432.

6. Sojoudi H, Nemani S. K., Mullin K, Wilson M. G, Al-Adwani H, et al., A micro/nanoscale approach for studying scale formation and developing of scale-resistant surfaces, ACS Applied Materials \& Interfaces, vol. 11, 2019, pp. 7330-7337.

7. Zhou H, Liao Z, Fang C, Li H, Feng B, et al., Pulse electroplating of Ni-W-P coating and its anti-corrosion performance, Transactions of Nonferrous Metals Society of China, vol. 28, 2018, pp. 88-95.

8. Fashu S, Mudzingwa L, Khan R, Tozvireva M, Electrodeposition of high corrosion resistant Ni-Sn-P alloy coatings from an ionic liquid based on choline chloride. Trans. IMF, vol. 96, 2018, pp. 20-26.

9. Pawlowski L, "The Science and Engineering of Thermal Spray Coatings", $2^{\text {nd }}$ ed, John Wiley \& Sons: Hoboken, NJ, USA, 2008.

10. W. M. Morgans, "Outline of Paint Technology", $3^{\text {rd }}$ ed, Edward Arnold Publishers, London, 1990.

11. R Lambourne, T A Strivens, "Paint \& Surface coatings", $2^{\text {nd }}$ ed, Woodhead Publishing, UK, 1999.

12. Du Z, Wen S, Wang J, Yin C, Yu D, et al., The review of powder coatings. Journal of Materials Science and Chemical Engineering, vol. 4, 2016, pp. 54-59.

13. Takeshita Y, Sawada T, Handa T, Watanuki Y, Kudo T, Influence of air-cooling time on physical properties of thermoplastic polyester powder coatings. Progress in Organic Coatings, vol. 75, 2012, pp. 584-589.

\section{Published By:}

Blue Eyes Intelligence Engineering \& Sciences Publication (C) Copyright: All rights reserved.

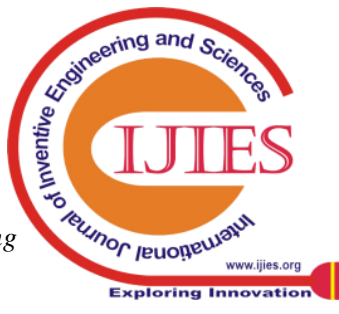


14. Dogan E, Ersin Acar A, The use of anhydride linkages to increase the glass transition temperatures of polymers containing carboxyl end groups: A perspective in powder coatings. Progress in Organic Coatings, vol. 76, 2013, pp. 513-518.

15. Shaffer S. J, Rogers M. J, Tribological Performance of various coatings in unlubricated sliding for use in small arms action components-a case study, Journal of Wear, vol. 263, 2007, pp. 1281-1290.

16. Sidhu B.S, Parkash S, Evaluation of corrosion behavior of plasma sprayed $\mathrm{Ni3Al}$ coating on steel in oxidation and molten salt environment at $900^{\circ} \mathrm{C}$, Surface and Coating Technology, vol. 166, 2003, pp. 89-100.

17. Gülenç, Behçet, Kahraman, Nizamettin, Wear behaviour of bulldozer rollers welded using a submerged arc welding process, Materials \& Design, vol. 24, 2003, pp. 537-542.

18. Shi Qiwu, Huang Wanxia, Zhang Yubo, Zhang Yang, Xu Yuanjie, et al., Curing of polyester powder coating modified with rutile nano-sized titanium dioxide studied by DSC and real-time FT-IR, Journal of Thermal Analysis and Calorimetry, vol. 108, 2011, pp. 1243-1249.

19. Grigoriev A.Y, Kavaliova I.N, Kupreev A.V, Dmitrichenko E. E, Friction and wear of polyamide- 6 powder coatings gradient-filled by metal nanofilms. Journal of Friction and Wear, vol. 34, 2013, pp. 107-113.

20. Tong Y, Bohmb S, Song M, Graphene based materials and their composites as coatings, Austin J Nanomed Nanotechnol, vol. 1, 2014 pp. 1003. ISSN: 2381-8956.

21. Aqueous emulsifier-free coating composition and its use in processes for the production of multilayer coatings, by Franjo Dipl Chem Dr Gol, Gerhard Laemmer, Werner Dipl Chem Dr Lenhard. (1995). Patent Number:DE4328092A1. https://patents.google.com/patent/DE4328092A1/en

22. Laurence W. McKeen, "Measurement of Coating Properties and Performance", 2nd ed, William Andrew Publishing, Norwich, NY, 2016, pp 227-259, https://doi.org/10.1016/B978-0-323-37126-1.00013-8

23. A. A. Elsayed, Improving of impact resistance of concrete using innovative shapes of steel fibres, IJIES, vol. 3, 2015, pp. 1-6.

24. Akkus M, Akbulut T, Candan Z, Application of electrostatic powder coating on wood composite panels using a cooling method. Part 1 : Investigation of water intake, abrasion, scratch resistance, and adhesion strength, BioRes, vol. 14, 2019, pp. 9557-9574.

25. K.V. S. N. Raju, M. Yaseen, Scratch hardness of paint coatings: effect of ageing and film thickness, Progress in Organic Coatings, vol. 21, 1992, pp. 37-51.

26. Berman Diana, Erdemir Ali, Sumant Anirudha, Graphene: A new emerging lubricant. Materials Today, vol. 17, 2014, pp. 31-42.

\section{AUTHORS PROFILE}

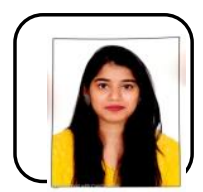

K. Samhitha Reddy, is currently pursuing final year of B.Tech in the field of Chemical Engineering at Chaitanya Bharathi Institute of Technology (A) During the course of her engineering, she has attended National Workshop on "Recent Advances in Chemical Process simulation Using Aspen Plus". She has completed a 4-week internship on Size Reduction with the MSAT (Process Engineering) Department, CTO Unit II at Dr. Reddy's laboratories limited in June 2018. She has also been part of Live Research Work being held in the department of Chemical Engineering on Surface Coatings and as part of it, she has also presented her paper in International conference RACE-2020. Her area of interest includes Coating Technology, Environmental Engineering, Process and Equipment Design, Petroleum engineering.

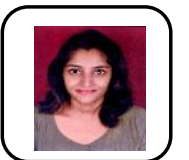

V. Shreya Reddy, is currently pursuing final year of B.Tech in the field Chemical Engineering at Chaitanya Bharathi Institute of Technology (A). During the course of her engineering, she has attended National Workshop on "Recent Advances in Chemical Process Simulation Using Aspen Plus". She has also been part of Live Research Work being held in the department of Chemical Engineering on Surface Coatings and as part of it, she has also presented her paper in the International conference RACE-2020. Her area of research/interests includes Surface Coating Technology, Food Technology, Petroleum Engineering, Textile Engineering, Environmental Engineering.

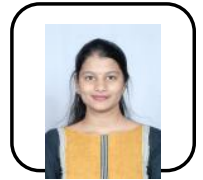

Sujitha. J, is currently pursuing final year of B.Tech in the field Chemical Engineering at Chaitanya Bharathi Institute of Technology (A). During the course of her engineering, She has attended National Workshop on

Published By:

Blue Eyes Intelligence Engineering

\& Sciences Publication

"Recent Advances in Chemical Process simulation Using Aspen Plus", She has completed 8 week internship at IICT, Hyd on Parameters of erification Reaction. She has also been part of Live Research Work being in the department of Chemical Engineering on Surface Coatings and as part of it, she has also presented her paper in the International conference on 2020. Her area of interest includes Coating Technology, Food technology, Industrial Pollution Control, Petroleum Engineering.

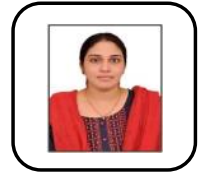

Dr. Madhuri Pydimalla, received her Bachelor's degree from Osmania university and Master's degree from JNTUH in the field of Chemical Engineering. She was awarded $\mathrm{PhD}$ in the research area of "Pulp and Paper Technology" from BITS PILANI in Sep 2019 She has total 12 yrs of teaching experience in academic field working as Assistant Professor in Chaitanya Bharathi Institute of Technology, Hyderabad and concurrent 6 years of research experience at BITS PILANI- Hyderabad Campus. She has published 06 research papers in reputed International SCI \& Scopus indexed journals and presented her research work in 10 Conferences (05 international and 05 National). Her area of research include Pulp \& Paper, Reaction Kinetics, Seperation processes, Surface coatings, Biofuels. 